\title{
An investigation of the effect of pit latrine additives on VIP latrine sludge content under laboratory and field trials
}

\author{
BF Bakare ${ }^{1 *}$, CJ Brouckaert $^{1}$, KM Foxon $^{1}$ and CA Buckley ${ }^{1}$ \\ 'Pollution Research Group, School of Chemical Engineering, University of KwaZulu-Natal, Durban 4041, South Africa
}

\begin{abstract}
Sludge content in VIP latrines is degraded mainly under anaerobic conditions and the process is relatively slow. At varying stages of digestion within pit latrines, sludge accumulates and odour and fly nuisance may occur which could pose risks to public health and the environment. Management of accumulated sludge in pit latrines has been a major problem facing a number of municipalities in South Africa and is also a global issue. Manufacturers of various commercial pit latrine additives claim that by addition of this product to pit content, accumulation rate and pit content volume can be reduced, thereby preventing the pit from ever reaching capacity. This paper presents a comprehensive study conducted to determine the effects of additives on pit contents under laboratory and field conditions. By conducting both laboratory and field trials, it was possible to identify whether there is any acceleration of mass or volume stabilisation as a result of additive addition, and whether any apparent effect is a result of biodegradation or of compaction. The results indicated that neither laboratory trials nor field trials provided any evidence that the use of pit additives has any beneficial effect on pit contents. The reasons why additives seem to not have any beneficial effects are also discussed.
\end{abstract}

Keywords: additives, digestion, pit content, sludge, public health, VIP latrine

\section{INTRODUCTION}

In South Africa, where the provision of adequate sanitation facilities to all is considered to be a fundamental human right, it is important to look at the provision of sanitation facilities holistically, and to derive scientifically-based approaches towards managing these sanitation facilities. In South Africa, the provision of adequate, appropriate, effective and sustainable sanitation facilities for all citizens is mandatory, and ventilated improved pit latrines are the minimum acceptable level of sanitation delivery in the country (DWAF, 2003). Many of the municipalities in South Africa are still struggling to reach their goal of providing basic sanitation to all, and there is an urgent need to plan and budget for a number of issues related to ventilated improved pit latrines that have been provided, before or when they become full. Management of accumulated sludge in pit latrines has become a major problem for many South African municipalities. The major problem has been on how to handle pit latrine sludge, and what disposal options are appropriate. Various disposal options have been proposed, including discharging sludge to sewer, sea outfall, wastewater treatment plant, burial onsite, transporting to landfill sites, deep row entrenchment for agroforestry and further dewatering and treatment/processing to produce agricultural fertilizers (DWAF, 2007).

Apart from these proposed disposal options, there are a number of pit additives available on the market, which manufacturers claim have the ability to reduce the volume of pit sludge content, and therefore the rate at which sludge accumulates in the pit, as well as to eliminate odour and fly problems. However, the claimed effectiveness of these pit additives has

\footnotetext{
* To whom all correspondence should be addressed. Current affiliation: Faculty of Engineering, Department of Chemical Engineering, Mangosuthu University of Technology, P.O. Box 12363 Jacobs, Durban 4026, South Africa e-mail: bfemi@mut.ac.za Received 2 September 2014; accepted in revised form 10 June 2015
}

not been conclusively and scientifically demonstrated, and the findings from the few available studies previously conducted, as presented in the literature, are controversial. The study conducted by Taljaard et al. (2003) did not provide strong evidence to support the claims stated by various manufacturers of pit additives; however it was noted that there was reduction in odour and flies in treated pits. The study involved both laboratory and field trials. In another laboratory study conducted by Sugden (2006) to investigate the efficacy of bio-additives designed to reduce sludge volumes in pit latrines and septic tanks by enhancing the anaerobic digestion process taking place, it was found that though all four stages of anaerobic digestion took place in all of the laboratory test units, there was no evidence to show that any of the bio-additives either enhanced or inhibited the anaerobic digestion process. Foxon et al. (2009) also concluded from laboratory experiments that commercial pit latrine additives were unable to accelerate the biodegradation rate and mass loss from samples of pit latrine sludge.

Despite the results presented in the scientific literature which suggested that pit latrine additives are not effective for reducing accumulation of sludge within a pit, a number of role players in the industry still believe that the use of these products might be beneficial. Faced with these controversies, this study endeavoured to conduct a comprehensive experiment which investigated the effects of additives on pit contents under both laboratory and field conditions, and also to provide a scientific basis for understanding the possible outcomes of using pit additives.

\section{MATERIALS AND METHODS}

In order to evaluate the efficacy of pit latrine additives in treating pit sludge content, two different trials were conducted. The first was a laboratory trial with sludge collected from a pit located in Durban, South Africa. The sample was taken from the surface of a pit beneath the pit pedestal. Samples were collected in plastic bags and placed in buckets 
which were tightly sealed to limit the exposure of collected sludge samples to air. The samples were thoroughly mixed in order to obtain homogeneity of sludge content in each treatment and replicates. After mixing, the sludge sample was divided into sub-samples of known mass (approximately $300 \mathrm{~g}$ each) and then placed in $300 \mathrm{~m} \ell$ screw-top plastic jars. The mass of the jar was measured before and after being filled with the mixed pit latrine sludge. The experiment was divided into different treatments (i.e. with different additives and reference treatments). Two different pit latrine additives were selected from a set of available commercial pit latrine additives. To maintain commercial confidentiality, these are referred to as Product A and Product B. Pit latrine additive dosage rate was determined as mass of additive per surface area of the pit $\left(\mathrm{g} \cdot \mathrm{m}^{-2}\right)$, based on the manufacturer's recommended dosage, and the same dosing rate was applied to the surface area of the jars.

An average value of $1.2 \mathrm{~m}^{2}$ was assumed for the surface area of the pit, based on the common value for pit designs in Durban, South Africa, where the study was conducted. The calculated recommended dosage for each additive was then added to the prepared sludge samples for the additive treatment placed in the jars. For Product A, each jar contained a known mass of sludge with $0.4 \mathrm{~g}$ of Product $\mathrm{A}$ in $10 \mathrm{~m} \ell$ of water added. Another set of jars contained a known mass of sludge with $0.02 \mathrm{~g}$ of Product B in $10 \mathrm{~m} \ell$ of water. A reference treatment in which $10 \mathrm{~m} \ell$ of water only was added to the sludge was included to determine whether there was any effect of adding water without additives. A control set of test units was also included in the experimental set-up where neither water nor additive was added to the sludge in the jars. This was done in order to quantify the effect of natural degradation and dehydration of pit latrine sludge. Five replicates of each test were performed. All the jars were incubated for 30 days at approximately constant temperature in a fume cupboard, and the mass of each jar was recorded over time. The rate of mass loss was calculated as the change in mass of jar content over defined periods of time for each jar, and expressed in grams per day per jar.

The second part of the study was a field trial, in which 30 pit latrines which were still in use were selected from a community within eThekwini Municipality, in order to obtain field results for the effect of the pit additives to compare with the laboratory results. The same pair of additives used in the laboratory trials was used in the field trials. According to the two additive suppliers, the sludge content in the pit latrine should be sufficiently wet, and if it is known that any chemical or other substances has been added to the sludge in the pits, a considerable amount of water needs to be added before the treatment commences. Therefore all of the pits, except the control pits (which were left untreated with either water or additives), were flushed with $20 \ell$ of water to mitigate the effects of whatever substances/chemicals may have been added previously and also to equalise the effect of water on the shape/level of sludge originally present in the pit latrines. From the 30 pits selected for this study, 2 sets of 8 pits were each treated with Additive A and B, respectively, a set of 7 pits was treated with water only, and a further 7 were used as the untreated control set. Since the additive suppliers indicated that the additives should be added with water to the sludge contents in the pit latrines, an equal amount of water was used to mix the two additives used in this study. $10 \ell$ of water was used to slurry the additive before it was poured into each pit. $10 \ell$ of water was used for each of the water-only pits. The field trials were carried out over a period of 6 months. Measurements of the sludge present in all of the pits were made before any treatment, after initial flushing with $20 \ell$ of water, after 3 months and at the end of the 6-month period.

Two measurement techniques were used; the first method involved measuring the distance between the top of the pedestal and the surface of the pit contents at 3 different locations within an area of approximately $0.06 \mathrm{~m}^{2}$ using an infrared laser distance meter. Figure 1 presents a schematic diagram of how measurements were taken using the laser meter. These measurements were averaged so as to give an indication of the distance between the top of the sludge heap and the pedestal. The difference in sludge heap height was calculated as an indication of the rate of reduction of sludge content in the various VIP latrines.

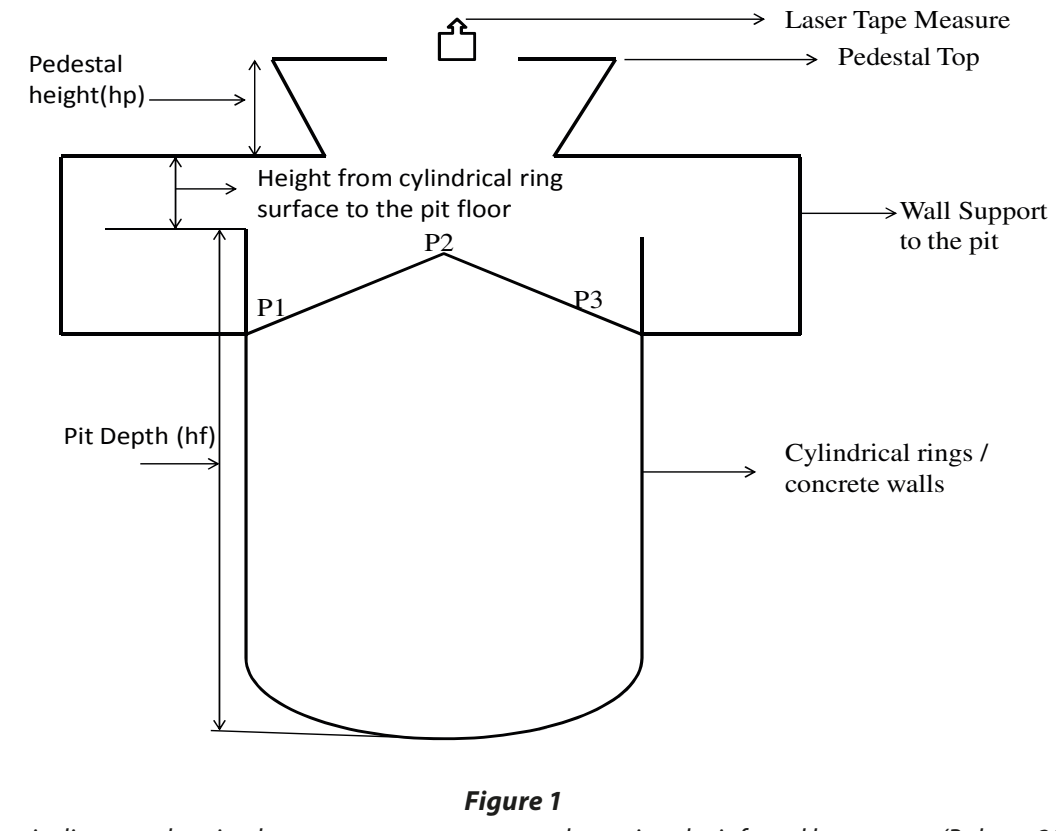

Schematic diagram showing how measurements were taken using the infrared laser meter (Bakare, 2014) 
The second approach used for taking measurements during the field trials involved making use of stereoscopic digital photographs to measure the spatial coordinates of any number of points on the surface of the sludge in the pit latrine. The points were then use to map out the shape of the surface of the pit content in 3 dimensions. Figure 2 presents the stereographic image equipment.

The digital camera was lowered on a supporting boom through the toilet pedestal. The boom was supported by a structure which could locate the camera precisely and reproducibly in the same position on subsequent visits to the same latrine. The camera boom was able to rotate to several positions which had been pre-set and could be locked by a locating pin. On every visit the floor was marked with a dot of paint at each foot of the supporting table to ensure that for subsequent visits the supporting table was placed at the same position. The camera support system allowed the camera to be tilted at a few pre-set angles to allow imaging for different levels in the pit. A trigger cable allowed the photograph to be initiated from outside the pit. For each pit, 8 images were recorded; 2 photographs were taken on each of 4 sides (forwards, backwards and to either side) and the 2 images were horizontally displaced by a known distance. The whole procedure was calibrated beforehand by images of a surface where the positions of the points were precisely known, and preliminary calibrations indicated that points on a surface $300 \mathrm{~mm}$ from the camera were located within a tolerance of about $0.7 \mathrm{~mm}$ when the displacement of the camera between images was $10 \mathrm{~mm}$. The pictures taken were uploaded to a computer for analysis. Figure 3(a) shows a single image of the surface of a pit latrine indicating the back, left, front and right sides in the pit latrine. The squares of yellow paper that are seen in the pictures were accurately cut and dropped into the pit, to provide reference distances that were used to check the triangulation results. Once the pictures were downloaded to the computer, points were selected in order to perform the triangulation calculations; an example of stereographic images of a pit surface showing how the points were selected for triangulation calculations is presented in Fig. 3(b).

The triangulation calculation determined the distance between the camera and any point on the surface of the pit contents. The surface map generated after performing the triangulation calculation is as shown in Fig. 4. The vertical distance between the heights of all of the points analysed was then averaged as an indication of the height of the pit contents. The change in the calculated average vertical distance between the heights of all of the points analysed was then used as an indication of the rate of accumulation of sludge content in the various VIP latrines investigated.

\section{LABORATORY RESULTS}

Figure 5 shows the cumulative mass loss from the test jars kept in a fume cupboard over 24 days. For clarity, the results for jars treated with additives are shown as lines, whereas the results for the controls are shown as point symbols.

The rates of loss of material from the jars, determined by linear regression of the data shown in Fig. 5, are presented in Table 1. As is also evident in Fig. 5, the group of jars treated with additive A appear to have a very slightly higher average mass loss rate than the other groups, although the confidence ranges for all of the groups overlap. A comparison of the slopes for the Additive A group and the untreated group using analysis of covariance (Brownlee, 1966) showed the difference to be insignificant $(p>0.4)$ The rate of mass loss for the Additive $B$ group was, in fact, less than that of the untreated group, although that result also proved to be statistically insignificant.

These results support the hypothesis of Foxon et al. (2009) that the quantity of active micro-organisms added in a dose of commercial pit latrine additive is insignificant compared to the naturally occurring micro-organisms present in pit latrine sludge. Thus, any enhancement of biological activity within a pit due to the pit latrine additives would be insignificant relative to natural degradation processes occurring within the pit as a result of the presence of naturally occurring organisms.

\section{FIELD RESULTS}

The second trial conducted made use of the same pit latrine additives; however, randomly selected pit latrines within a community were dosed with the same set of additives used in the laboratory trials. Two different methods of measurement were used to quantify the effect of direct addition of pit latrine additives to sludge contents in the pit. Figure 6 presents the sludge reduction results obtained using the infrared laser distance

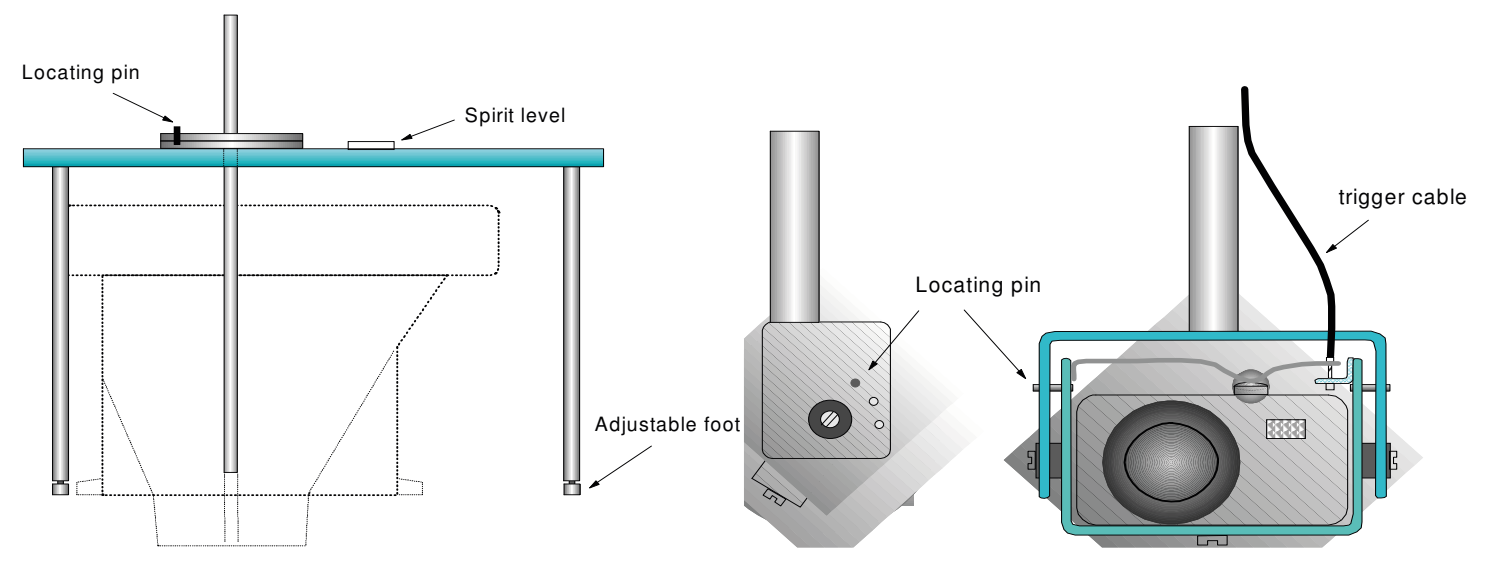

Figure 2

Stereographic equipment set-up (Bakare, 2014) 
(a)
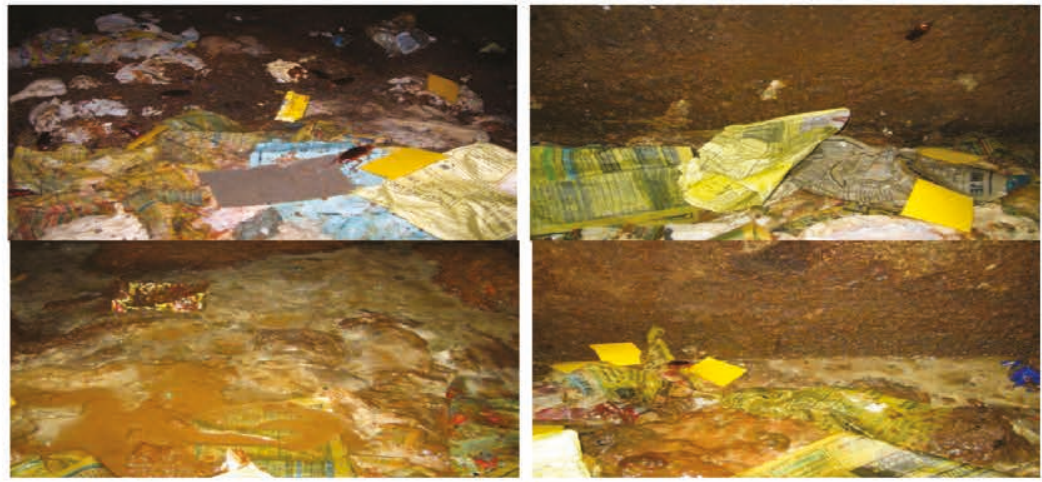

(b)

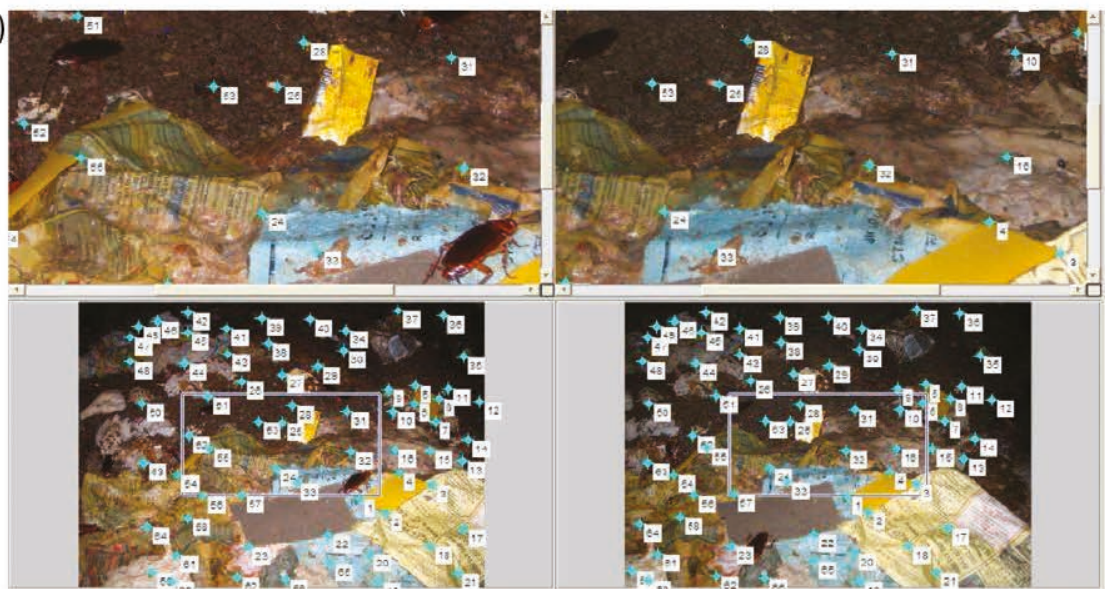

Figure 3

(a) Single images of the pit surface (Clockwise from the top left: back; left, front and right sides of pit), (b) Stereographic images of a pit surface showing the points selected for triangulation calculations (Bakare, 2014).

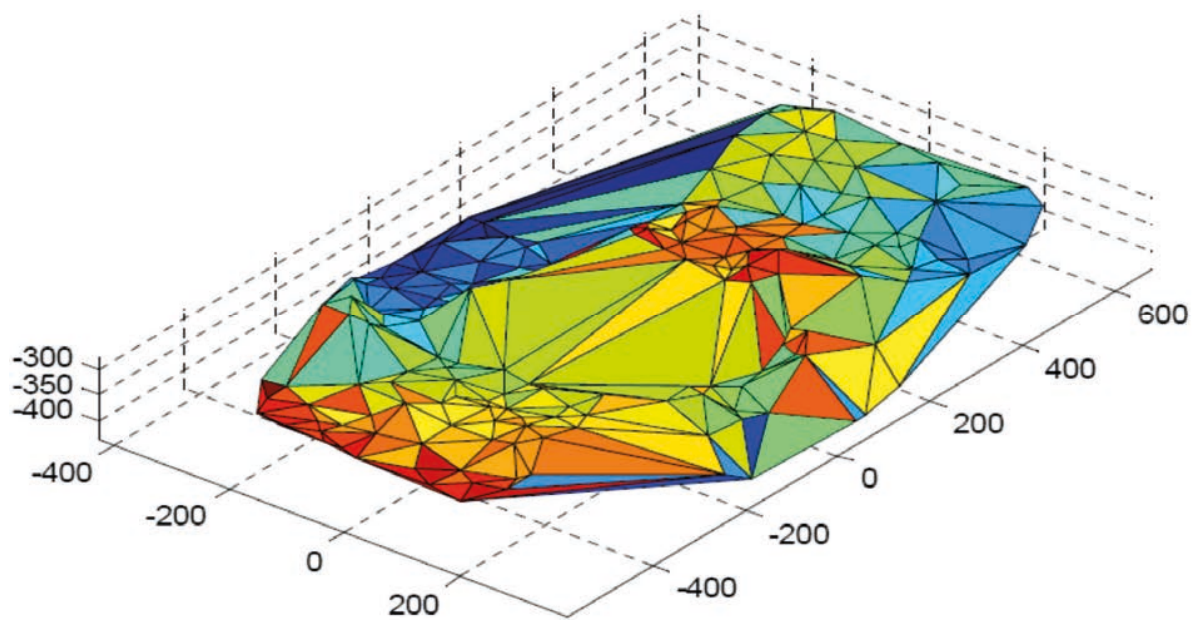

Figure 4

Surface map generated by triangulation calculations of selected points on the images taken of pit contents by the stereographic camera (Bakare, 2014)

TABLE 1

Regressed rates of mass loss for pit latrine sludge in laboratory trials

\begin{tabular}{|l|c|c|}
\hline \multirow{2}{*}{ Treatment } & \multicolumn{2}{|c|}{ Regressed rate of mass loss $\left(\mathbf{g} \cdot \mathbf{j a r}^{-\mathbf{1}} \cdot\right.$ day $^{-1}$ ) } \\
\cline { 2 - 3 } & Mean & $\mathbf{9 5 \%}$ confidence interval \\
\hline Untreated & 0.619 & $0.584-0.654$ \\
\hline Water only & 0.574 & $0.533-0.616$ \\
\hline Additive A & 0.658 & $0.620-0.696$ \\
\hline Additive B & 0.593 & $0.561-0.627$ \\
\hline Pooled results & 0.620 & $0.601-0.639$ \\
\hline
\end{tabular}

http://dx.doi.org/10.4314/wsa.v41i4.10

Available on website http://www.wrc.org.za

ISSN 1816-7950 (On-line) = Water SA Vol. 41 No. 4 July 2015

Published under a Creative Commons Attribution Licence 
meter, for each of the treatments of the field trials.

The first 3 months indicated a net decrease in level across all treatments, except for the control pits in which there was a net increase in level. The consistent increase in level in the control pits was expected because they were in use, and no additives or water were added to them. However, it was observed that there was no significant decrease in level across all treatments after the first 3 months and until the end of the field trials. There was also no significant difference between the level changes for the pits into which additives were added and the pits into which only water was added.

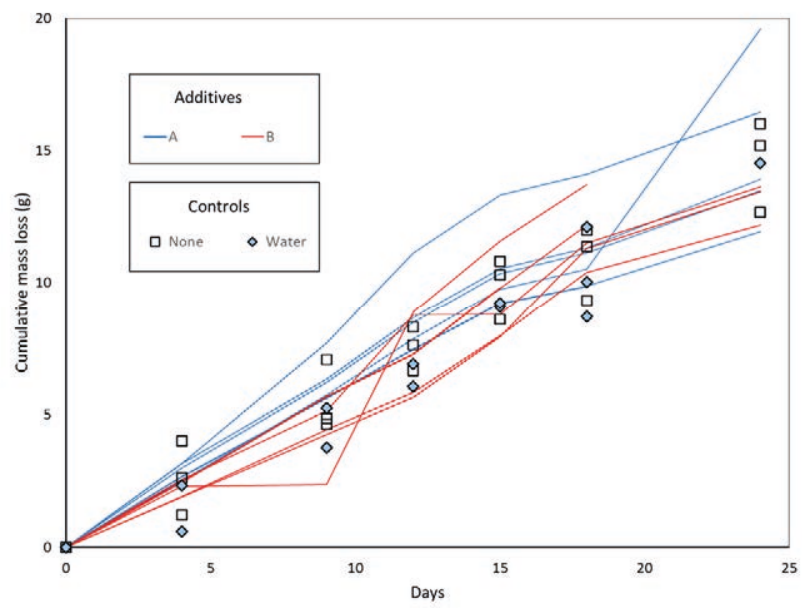

Figure 5

Cumulative mass loss from jars of pit latrine sludge with and without treatment by additives and water

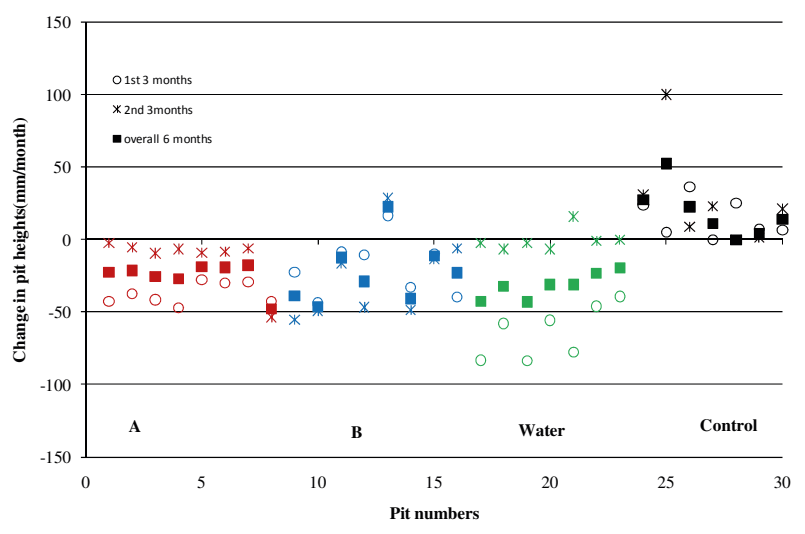

Figure 6

Change in pit latrine sludge level for all of the treatments for the field trials using the laser distance meter
These measurements could not show whether the apparent reduction in pit latrine contents volume was due to levelling of the pit contents through water addition or through enhanced biological degradation rates as a result of the water added. What they did show is that the apparent reduction in the level could not be attributed to the treatment with pit additives. A summary of the average overall sludge level changes obtained using the laser distance measure for each of the treatments of the field trials are presented in Table 2.

Figure 7 presents the result of the net sludge reduction per month in all of the pits using the stereographic imaging technique. Statistical analysis (ANOVA) was performed to determine whether there was a difference in the net change in level for any of the pits during the trials. The results showed that there were no significant differences between the three treatments and the control $(p>0.05)$ over the duration of the trial.

The most likely explanation for the apparent contradiction between the stereographic measurements and the laser level measurements is that the addition of water with mixing to the highest part of the surface caused it to be flattened. The stereographic measurements were able to compensate for this because they covered the entire surface, rather than just the mound immediately below the toilet pedestal.

\section{DISCUSSION}

The results obtained from the laboratory trials showed the distribution of the rate of mass loss for all four treatments. However, there was no statistically significant difference in the rates of mass loss between sludge samples receiving the different

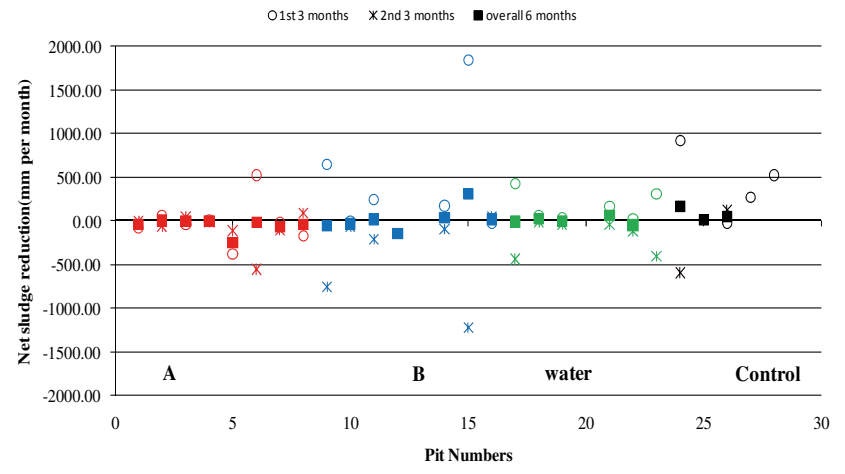

Figure 7

Net sludge reduction for all the treatments for the field trials using the stereographic imaging technique. It should be noted that some data points are missing in the above plot since: (1) during the course of the trials some pit latrine became so full that the camera could not be lowered; (2) There was a case in which the owner of the pit died and the pit was locked up.

TABLE 2

Overall changes in sludge level as measured with the laser distance meter

\begin{tabular}{|l|c|c|}
\hline \multirow{2}{*}{ Treatment } & \multicolumn{2}{|c|}{ Rise (+) or drop (-) in level over $\mathbf{6}$ months (mm) } \\
\cline { 2 - 3 } & Mean & $\mathbf{9 5 \%}$ confidence interval \\
\hline None & +131 & +79 to +184 \\
\hline Water only & -191 & -273 to -110 \\
\hline Product A & -150 & -96 to -104 \\
\hline Product B & -131 & -202 to -67 \\
\hline
\end{tabular}


treatments, or to which either of the two additives was applied.

Testing the effect of additives is much more difficult in the field than in the laboratory, but is necessary to counter the argument that there may be relevant aspects of field conditions that are not replicated in the laboratory. One of the significant measurement difficulties is the irregular geometry of pit contents, so that simple level measurements do not provide reliable information about sludge accumulation rates, unless the determination involves a very long time interval, perhaps 2 years or more. The stereographic measurement system was developed specifically to account for irregular geometry, and so allow accumulation rates to be estimated in a shorter time. The comparison between the results of the simple level measurements and the stereographic measurements confirms that using the simple level measurements can lead to erroneous conclusions.

These results support the findings of previous studies (Sugden et al. 2006; Foxon et al. 2009) that pit latrine additives do not assist in reducing pit filling rates and sludge volumes. However, only two additives were tested, and there may be others which would return a different outcome. Nevertheless, most pit additives claim to rely on the same principle as those tested: that is, seeding the sludge with selected microorganism species which are especially effective in catalysing degradation. It is therefore probable that the use of other additives in this class will show a similar outcome. The failure of the pit latrine additives to accelerate the degradation of pit latrine sludge noticeably suggests that the quantity of microorganisms added in a single dose of pit additive is insignificant compared to the quantity of micro-organisms naturally present in the sludge, and that the latter are very well adapted to the environment.

Bakare et al. (2012) indicated that less than $30 \%$, on average, of the sludge content in a pit latrine is biodegradable and that the biodegradable material is largely concentrated in the layer close to the surface. Hence, the residual biodegradability of material beneath the surface layer of the pit content is significantly lower when compared to the material in the surface layer of the pit. Thus, the addition of pit latrine additives to pit sludge content would not have any significant effect in reducing the mass or volume of the bulk of the buried material through biological degradation, since only the surface layer of pit contents will contain fresh material and mixing of sludge in pit latrines is very difficult to achieve.

It was observed, both during the sampling of sludge for the laboratory trials and during the field trials, that the latrine sludge contained a significant amount of solid household waste. The presence of non-degradable solid waste is a significant problem for any sludge management scheme, which will not be helped in any way by the use of additives.

This study has failed to provide any evidence that additives increase the rate of degradation over the rate which occurs spontaneously due to naturally occurring microorganisms. Even if more precise measurements over a longer trial were to reveal a measureable improvement, it would not be sufficient to justify the use of additives as part of a sludge management program. To be economically effective, the additive would have to completely prevent accumulation of sludge, and so eliminate the need to empty the pit. A typical additive treatment for a pit costs ZAR20 per month (and is much higher for some products) and over 5 years this will come to a total cost of ZAR1 200 without interest or ZAR 1500 (USD 200) including interest. A pit latrine can be completely emptied and the sludge content disposed of using manual or mechanical methods for approximately the same cost (Buckley et al., 2008).

\section{CONCLUSIONS}

Neither the laboratory trials nor field trials conducted provided any evidence that the use of pit additives has any effect in reducing the mass or volume of sludge in VIP latrines. There were no statistically significant changes in the rate of mass loss on sludge samples in the laboratory or in sludge content of the pit latrines in field trials, as a result of applying pit latrine additives. The significant reduction in sludge height in pit latrines, where water only was added, could not be attributed to volume reduction due an increased biodegradation rate. Instead, this observation is probably explained by flattening of the sludge surface in the pit.

\section{ACKNOWLEDGEMENTS}

The research was funded by the Water Research Commission through WRC Project K5/1745 entitled 'Understanding sludge accumulation in VIPs, urine diversion toilets and other onsite sanitation systems, and strategies to manage desludging in the future when pits are full', granted to Partners in Development. The support of and contribution by eThekwini Water and Sanitation Services and financial and technical support provided by Partners in Development is gratefully acknowledged. The author gratefully acknowledges the support of the Pollution Research Group, University of KwaZulu-Natal, Durban, South Africa, where the study was conducted.

\section{REFERENCES}

BAKARE BF (2014) Scientific and management support for ventilated improved pit latrines (VIP) sludge content. PhD thesis, University of KwaZulu-Natal, South Africa.

BAKARE BF, NWANERI CF, FOXON KM, BROUCKAERT CJ and BUCKLEY CA (2012). Variation in VIP latrine Sludge Contents. Water SA 38 (4) 479-486.

BROWNLEE KA (1966). Statistical Theory and Methodology in Science and Engineering. Willey, New York.

BUCKLEY CA, FOXON KM, BROUCKAERT CJ, RODDA N, NWANERI C, BALBONI E, COUDERC A and MAGAGNA D (2008) Scientific support for the design and operation of ventilated improved pit latrines (VIPs) and the efficacy of pit latrine additives. WRC Report No. TT357/08. Water Research Commission, Pretoria.

DWAF (DEPARTMENT OF WATER AFFAIRS AND FORESTRY, SOUTH AFRICA) (2003) Strategic Framework for Water Services. URL: www.dwaf.gov.za/documents/policies/strategic\%20framework\%20approved.pdf (Accessed 29 August 2014).

DWAF (DEPARTMENT OF WATER AFFAIRS AND FORESTRY, SOUTH AFRICA) (2007) Options for dealing with full pits. Draft guideline - emptying of pit latrines. Water Services WSDP support tool. URL: www.dwaf.gov.za/dir_ws/WSDP (Accessed 29 August 2014).

FOXON KM, MKHIZE S, REDDY M, BROUCKAERT CJ and BUCKLEY CA (2009). Laboratory protocols for testing the efficacy of commercial pit latrine additives. Water Sci. Technol. 35 (2) 228-235.

SUGDEN S (2006) Investigating the potential of bio-additives to prolong the life of pit latrines and septic tanks in emergency situations. London School of Hygiene and Tropical Medicine, London.

TALJAARD L, VENTER A and GORTON D (2003) Evaluation of different commercial microbial or microbial derived products for the treatment of organic waste in pit latrines. WRC Report No. 1377/1/05. Water Research Commission, Pretoria. 